\title{
HHS criticizes research centers for inaction on patient safety
}

The Office of the Inspector General of the Department of Health and Human Services (HHS) has criticized US research centers for failing to implement recommendations it made in 1998 to improve patient safety in clinical research. The charges appear in a new status report, which became the focus of the 3 May session of the House Government Reform Subcommittee, strongly suggesting that government oversight of human subject research may soon be stepped up even further. But some question whether the HHS expectations are realistic, given the complexity of implementing the recommendations.

After the 1998 recommendations were issued, the Office of Protection from Research Risks (OPRR) at the National Institutes of Health restricted federally funded research at several institutions, citing violations of federal rules for human subject research. The institutions targeted by the OPRR have all embarked on extensive reviews of their research oversight systems, usually increasing the staffing of institutional review boards (IRBs) and implementing educational programs for investigators working with human subjects. Many medical centers that were not cited by the OPRR have also carried out reforms in an effort to avoid having their own research suspended. Meanwhile, the Food and Drug Administration has made more on-site safety visits to research centers, increasing the number of investigations from 213 in 1997 to 336 in 1999.

But according to the HHS, these steps are not enough. The report concludes, "Overall, few of our recommended reforms have been enacted," and asserts that most IRBs are still overloaded with work and lack sufficient accountability and protection from conflicts of interest.

David Korn, the senior vice president for biomedical and health sciences research at the Association of American Medical Colleges, responds that although the report makes some valid points, "it tends to underestimate the extent to which both the agencies, that is the NIH and FDA, and the medical schools and teaching hospitals are attempting to improve." Korn adds that "you could argue that [the changes] are too slow, but I think change is happening."

The additional expense of implementing the changes could be a major factor in the delay. "There are financial costs and there are human costs to... what we and a dozen other institutions have gone through," says Richard Krugman, dean of the University of Colorado Health Sciences Center (UCHSC), one of the centers where research was restricted by OPRR. In addition to the cost of hiring additional staff to reduce IRB workload, Krugman told Nature Medicine that the suspension of research and the process of overhauling the UCHSC oversight system has placed considerable stress on researchers and administrators.

Compounding the problem, the cost of implementing the recommendations will probably have to be borne by UCHSC, as the center already receives the maximum federal reimbursement allowed for indirect costs of federally funded research. "If in fact Congress and the executive branch want everybody to ratchet up their compliance [with the
HHS recommendations], it would certainly be helpful to have some relief" from the added expenses, says Krugman.

Whether or not more money is made available, more changes seem inevitable. In addition to the congressional hearing, the National Bioethics Advisory Council is now undertaking a comprehensive review of existing human research regulations, the Institute of Medicine is launching a study on the issue, and the OPRR is being moved to the office of the Secretary of Health and Human Services, being renamed and appointing a new director and an advisory committee.

Alan Dove, Philadelphia

\section{Transplant organ allocation squabble continues}

Since 1994, the US Department of Health and Human Services (HHS) and the United Network for Organ Sharing (UNOS) have been locked in a dispute over how best to allocate donor organs in the US, and who is best qualified to set organ policy. Now it seems that the UNOS has gained the upper hand following congressional intervention.

In March, the HHS put into effect what it called a final rule, declaring HHS control over transplant organ allocation policy; the rule is opposed by the UNOS, the non-profit government contractor controlling the medical network that acquires and matches organs to patients. But in April, the House of Representatives passed the Organ Procurement and Transplantation Network Amendments Act of 1999, reserving organ policy decisions to the UNOS.

This is not the first time that Congress has intervened in the dispute. A 1998 attempt by the HHS to change UNOS policies (Nature Med. 4, 376; 1998) was suspended by a congressional moratorium pending requested fact-finding investigations by the $\mathrm{HHS}$ and the Institute of Medicine (IOM). An IOM report last year agreed with the HHS that UNOS geographical-preference policies needed to be altered, which led to the HHS' March declaration that it would establish an independent scientific review board to oversee UNOS policies.

The two groups disagree on how to balance conflicting goals-providing fair access to all patients while making best medical use of scarce organs. Ideally, organs should go to the sickest patients; survival rates, however, are best among those who are least desperate. The HHS has complained that the UNOS too often allows patients living nearby transplant surgery centers to receive organs in preference to those in greater need, but living farther away; the HHS contends the 'locals first' policy causes unnecessary deaths. Last year, the UNOS did increase the proportion of organs going to the most life-threatened patients, but it is adamant that the medical community it represents is best qualified to set organ policy.

Provisions of the new act must now be reconciled with those of a bill that may eventually emerge from the Senate. That legislation has been influenced by Senator Bill Frist (RTN), a heart-and-lung-transplant surgeon. Frist proposes that the UNOS set organ policy, but calls for a committee to arbitrate disagreements between the HHS and UNOS. However, voting on the bill has been delayed by Senator Russ Feingold (D-WI), who is concerned about the arbitration committee's makeup. His state is particularly unhappy with the HHS: Wisconsin has taken the HHS to court to maintain its 'locals first' preference.

Tom Hollon, Bethesda 